\title{
Quantitative and qualitative methods in the study of some dynamic systems
}

\author{
Dumitru BĂLĂ $\breve{~}^{1, a}$ \\ ${ }^{1}$ University of Craiova, Drobeta Turnu Severin, România \\ adumitru_bala@yahoo.com
}

Keywords: dynamic system, stability, periodic movements, percussive coupler

Abstract. In this paper we present several methods for the study of stability of dynamical systems. We analyze the stability of a hammer modeled by the free vibrator that collides with a sprung elastic mass taking into consideration the viscous damping too.

\section{Introduction}

We propose to study the stability of some dynamical systems described by differential equations. We will make some remarks regarding the study of the stability and will analyze specifically the stability of a vibropercutant system. The differential equations and systems of differential equations are nonlinear and further complicate because the initial and final conditions arise with discontinuities. The positions and speeds before and after the collision can be different..

\section{Presentation of the model}

We are studying the existence of the periodic regimes of movement in connection with a hammer modeled by the free vibrator that collides with a sprung elastic mass. With this model, the viscous damping will be further considered.

The system under discussion is made up of the mass $\mathrm{m} 1$, the vertical spring with an elastic constant noted $\mathrm{k}$, and the viscous damping with value $\mathrm{c}$, and the vibrator $\mathrm{m}_{2}$ the perturbation noted as $\mathrm{F}(\mathrm{t})=\mathrm{F}_{0} \cos \omega \mathrm{t}$ acts upon. It is assumed that the collision of these two masses is spontaneous and it occurs at the same time with the value $\mathrm{R}(0<\mathrm{R}<1)$.

If we name $\mathrm{q}_{1}$ and $\mathrm{q}_{2}$ the abscissae of the two masses measured when the spring is not diformed, the differential equations of the movement between two successive collisions will be

$$
\begin{aligned}
& m_{1} \ddot{q}_{1}+c \dot{q}_{1}+k q_{1}=-m_{1} g \\
& \mathrm{~m}_{2} \ddot{q}_{2}=F_{0} \cos \omega t-m_{2} g
\end{aligned}
$$

If the following notes are added:

$$
h=\frac{c}{2 m_{1}}, \quad \mathrm{p}=\sqrt{\frac{\mathrm{k}_{1}}{\mathrm{~m}_{1}}-h^{2}}, \quad \mathrm{f}_{0}=\frac{F_{0}}{m_{2} \omega^{2}}
$$

the differential equations (1) and (2) can be written

$$
\ddot{q}_{1}+2 h \dot{q}_{1}+\left(p^{2}+h^{2}\right) q_{1}=.-g
$$

and

$$
\ddot{q}_{2}=f_{0} \cos \omega t-g
$$

The collisions occur metween masses $\mathrm{m}_{1}$ and $\mathrm{m}_{2}$ which form a percussive coupler corresponding to the unilateral link function

$\mathrm{F}\left(\mathrm{q}_{1}, \mathrm{q}_{2}\right)=\mathrm{q}_{2}-\mathrm{q}_{1} \geq 0$ 
Since periodical movements are of paramount interest, it is enough to study one single aspect of movement 1 , which is obviously more complex compared to that of the distracting force, i.e.

$r T=r \frac{2 \pi}{\omega}(\mathrm{r}=1,2, \ldots)$ as present in [14]. Consequently, the study may consider the first period which begins in the moment $\mathrm{t}=\mathrm{t}_{0}$ and ends in $\mathrm{t}_{1}=\mathrm{t}_{0}+\mathrm{rT}$. The condition of existence and stability of the device's periodic movements that collide with the sprung elastic mass will thus be determined, while also taking viscous damping into consideration. In order for the movement to be recurrent, one of the major conditions is for the period, i.e. the amount of time between two consecutive collisions, to be a multiple of the force's period of variation, i.e.

$$
r T=r \frac{2 \pi}{\omega}(\mathrm{r}=1,2, \ldots)
$$

It is also necessary that the collisions take place in the same position and with the same velocity. Therefore for $\mathrm{t}=\mathrm{rT}$, one should consider $\mathrm{q}_{1}=\mathrm{q}_{2}=\mathrm{q}_{0}$ and $\dot{q}_{1}=\dot{q}_{10}, \dot{q}_{2}=\dot{q}_{20}$. Once the initial conditions outlined, we determine the laws of movement; after considering the final conditions for the period under discussion we obtain

$$
\begin{aligned}
& \dot{q}_{20}=\dot{q}_{20}^{\prime}-g r T \\
& \dot{q}_{20}^{\prime}=f_{0} \omega \sin \omega t_{0}+\frac{1}{2} g r T
\end{aligned}
$$

The following relationship is reached:

$$
\dot{q}_{10}=-\frac{g r T}{2 m}(H-1)
$$

in which

$$
\begin{gathered}
H=\frac{\frac{h}{p} \sin \text { prT - sh hrT }}{\cos \text { prT - ch hrT }} \\
\dot{q}_{10}^{\prime}=-\frac{g r T}{2 m}(H+1) \\
\dot{q}_{20}=-\frac{g r T}{2 m}\left(H+\frac{1+2 m-R}{1+R}\right), \\
\dot{q}_{20}^{\prime}=-\frac{g r T}{2 m}\left(H+\frac{1-2 m-R}{1+R}\right)
\end{gathered}
$$

We will still further outline what results from the relations (10), (12), (13) and (14):

- relation (10) indicates the formula used to calculate the velocity of $\mathrm{m}_{1}$ before collision;

- relation (12)indicates the formula used to calculate the velocity of $\mathrm{m}_{1}$ aftre collision;

- relation (13) indicates the formula used to calculate the velocity of $\mathrm{m}_{2}$ before collision;

- relation (14) indicates the formula used to calculate the velocity of $\mathrm{m}_{2}$ after collision.

In order for the periodical movement to be completely known, one should also calculate the moment $t_{0}$ of the first collision. One should take equation (9) into consideration; if one considers the expression $\dot{q}_{20}^{\prime}$ in relation (14)

$$
\sin \omega \mathrm{t}_{0}=-\frac{g r T}{2 m}\left[H+\frac{(1-R)(1+m)}{1+R}\right]
$$

can be deduced.

Obviously, the periodical movement will be possible if the term to the right in equation (15) is sub-unitary in module, i.e. 


$$
\left|-\frac{\operatorname{gr} T}{2 m}\left[H+\frac{(1-R)(1+m)}{1+R}\right]\right| \leq 1
$$

\section{Method of study}

The mathematical description of certain mechanical systems technically applicable is difficult. Generally speaking, the mechanical systems in engineering are mathematically described by differential equations or by systems of differential equations as presented in [1], [2], [8], [10] and [17]. Generally, these systems are non-linear and thus difficult to solve. Solving these systems means finding the time function or functions which, if replaced in the equations, proves the validity of these systems of equations. These would be the quantitative methods.

Not rare are the cases when we cannot find the exact solution, and then we look for partial solutions, or we use qualitative methods. One of the qualitative methods in the theory of stability as presented in [1], [2], [8], [10] and [17]. The following notations are used in reference materials: $q=q(t)$ is the function of time which describes motion;

$\dot{q}=\frac{d q}{d t}$ is velocity;

$\ddot{q}=\frac{d^{2} q}{d t^{2}}$ is acceleration.

With systems which present no discontinuities, the method that employs the Liapunov function is often applied. Remarkable results have been obtained, as presented in [1], [3], [8] and [17]. Liapunov's theory states that if there is a function which meets the conditions in Liapunov's theorems, then it can be stated whether movement is stable, asymptomatically stable, or unstable. The theory does not indicate how to find Liapunov's function. Some papers, as presented in[1], [2], [3], [4] and [8] provide a few examples in which Liapunov functions are created. The Liapunov function method cannot be applied with vibropercutant systems. If collisions occur, one can no longer talk about continuous cases, discontinuities appear, and the requirements in Liapunov's theory can no longer be met.

The dynamic systems that perform vibrant movements, repeated collisions, and in which the influence of the collisions is obvious and thus impossible to be neglected, are called vibropercutante systems. In order for vibropercutante movements to be generated, the movement of the system does not need to be vibrant. Consequently the vibropercutante movements are generated as a result of collisions. Due to the percussive interactions, the mechanical systems perform free vibropercutante movements without any outer stimuli. Since energy dissipates through collision and friction, the resulting movements have a temporary character and prove insignificant in terms of applications.

In the model above analyzed, after collision, the pre-collision velocity generally differs from the post-collision one. Consequently, velocity to the ;left differs from velocity to the right. Mr. Liviu Brindeu's method is applied, as presented in [14].

In fact, the starting point is represented by the system of differential equations as resulting from relations (1) and (2) in order to study the stability of this system. Since collisions occur, we are thus faced with discontinuities, and special techniques are to be employed. Certain conditions of periodicity are also to be considered in order to reach the characteristic equation, and then Schur's criterion is employed.

\section{Conclusions}

Starting from the system of differential equations given by the relations (1) and (2), the present paper studies the stability of this system. Since collisions occur, and hence the discontinuities, special techniques are needed. Conditions regarding periodicity are to be considered, too, in order to find the characteristic equations, and then Schur's criterion is employed. 
Acknowledgment: This work was partially supported by the grant number 3C/27.01.2014, awarded in the internal grant competition of the University of Craiova.

\section{References}

[1] Bălă Dumitru, Geometrical Methods in the Study of Vibrant and Vibropercutante Systems Movement, Universitaria Publishing House, Craiova, 2006.

[2] Bălă Dumitru, Geometric methods in study of the stability of some dynamical systems, An. Şt. Univ. Ovidius Constanţa, Vol.17(3), 2009, pp. 27-35.

[3] Bălă Dumitru, The study of the stability of some dynamical systems with applications in economy, Analele Universităţii din Craiova, Seria: Stiinţe Economice, Anul XXXV, Nr.35, 2007, Volumul 7, 2007. pp. 1541-1552.

[4] Bălă Dumitru, Geometrical methods in the study of some dynamical systems with applications in economy, Theoretical and Applied Economics/Economie Teoretică şi Aplicată, Anul XV, Nr.7(524), 2008, pp. 55-60

[5] Bălă Dumitru, The role of dynamical systems theory in economics, Economics, Management, and Financial Markets, Volume 5,Number 3, 2010, pp. 249-254.

[6] Bălă Dumitru, Optimum productivity, performance, and milling machine, Official journal of the contemporary science association-New York, Economics, Management, and Financial Markets, Volume 5, Number 2-June, 2010, pp. 316-321.

[7] Bălă Dumitru, The application of mathematical models in describing real economic processes, Official journal of the contemporary science association-New York, Economics, Management, and Financial Markets, Volume 5, Number 1-March, 2010, pp. 164-169.

[8] Bălă Dumitru, The study of the stability of some dynamical systems with application in economy using geometrical methods, Proceedings of the twelfth Symposium of mathematics and its applications, Timişoara, November, 5-7, 2009, pp. 288-293.

[9] Danca Marius-Florin, Dynamic Discountinuous Systems, Risoprint Publishing House, Cluj Napoca, 2004.

[10] Georgescu Adelina, Moroianu Mihnea, Oprea Iuliana, The Theory of Bifurcation. Principles and Applications, Pitesti University Publishing House, Piteşti, 1999.

[11] Pop Camelia, Petrişor Camelia, Bălă Dumitru, Hamilton-Poisson Realizations for the Lü System, Mathematical Problems in Engineering , vol. 2011, http://www.hindawi.com/journals/mpe/2011/842325/.

[12] Pop Camelia, Anania Aron, Petrişor Camelia, Geometrical aspects of the ball-plate problem, Balkan Journal of Geometry and Its Applications, Vol.16, No 2, 2011, pp. 114-121.

[13] Pop Camelia, Petrişor Camelia, Bălă Dumitru, A Geometric Approach of some Dynamics Arising from Engineering and Biology, Selected Topics in Mathematical Methods and Computational Techniques in Electrical Engineering, 2010, pp. 78-82.

[14] Silaş Gheorghe, Brîndeu Liviu, Vibropercutante Systems, Technological Publishing House, Bucureşti, 1986.

[15] Silaş Gheorghe, Brîndeu Liviu, Considerations on the use of unilateral link function in the study of collision, $4^{\text {th }}$ Conference on Vibration in Mechanical Engineering, Timisoara, November, 1982, pp. 67-72.

[16] Silaş Gheorghe, Groşanu I., Mechanics, Didactic and Pedagogic Publisher, Bucharest, 1982.

[17] Udrişte Constantin, Atlas of Magnetic Geometric Dynamics, Geometry Balkan Press, Bucarest, Romania, 2001. 